\title{
A PRIVATIZAÇÃO DO SANEAMENTO
}

\author{
Oscar Adolfo Sanchez \\ Doutorando do Departamento de Ciência Política da USP
}

\begin{abstract}
Resumo: O texto analisa as tentativas de privatização de sistemas municipais de saneamento básico no Estado de São Paulo entre 1995 e 1998, salientando a atuação, estratégias e constrangimentos enfrentados pelos principais atores envolvidos, isto é, as empresas multinacionais interessadas em expandir seus mercados ante a resistência dos setores que defendem o status quo.

Palavras-chave: saneamento básico; privatizações; municípios.
\end{abstract}

$\mathrm{O}$ objetivo do artigo é analisar as tentativas de privatização de sistemas de saneamento básico em municípios do Estado de São Paulo, desde a promulgação da Lei de Concessões de Serviços Públicos ( ${ }^{\circ}$ 8.987), em 1995, até o ano de 1998, evidenciando principalmente a atuação, as estratégias e os constrangimentos institucionais enfrentados pelos atores envolvidos.

O setor de saneamento, estatal desde o primeiro governo Vargas, com a promulgação da referida lei - que estabeleceu diretrizes para a concessão de serviços públicos e solucionou em grande parte o marco legal requerido para a privatização de sistemas municipais de saneamento - passou a ser o alvo de empresas nacionais e multinacionais, que se empenharam em abrir o novo e expressivo mercado paulista, formado por uma grande empresa estadual, a Saneamento Básico de São Paulo (Sabesp), e quase três centenas de serviços municipais autônomos.

A opção privada na gestão de sistemas de saneamento parecia um caminho inevitável. Ela fazia parte de um processo amplo de reforma do Estado em que temas como a desestatização, a modernização do setor público e a desregulamentação passaram a fazer parte da ordem do dia. Nesse contexto, não existiam muitos motivos para se acreditar que especificamente esse setor seguiria um caminho diferente ao de outros setores da infra-estrutura geridos pelo Estado, que passaram para a iniciativa privada em poucos anos. Da mesma forma, observando algumas ex- periências internacionais, países que adotaram políticas econômicas similares à adotada no Brasil, como Argentina, Chile, México, Peru e outros países latino-americanos e do leste europeu, privatizaram grande parte dos seus serviços de saneamento.

No Brasil, no entanto, e até o final de 1998, não havia um marco regulatório que permitisse privatizar as companhias estaduais concessionárias de serviços de saneamento (as Cesbs). Apesar de alguns governos de Estado terem interesse em seguir esse caminho, como os do Rio de Janeiro, Espírito Santo, Tocantins e Bahia, entre outros, disputas entre governadores e prefeitos envolvendo controvérsias legais sobre quem era de fato o verdadeiro detentor da titularidade do poder concedente, principalmente nas regiões metropolitanas, provocaram, por longo tempo, um impasse nas privatizações. Pode-se, ainda, observar que os esforços do Governo Federal nesse período se dirigiram para criar os marcos regulatórios apropriados que tornassem viável a privatização de empresas estatais de outros setores da infra-estrutura, menos conflituosos, deixando o de saneamento básico para último termo. De qualquer forma, esse impasse não afetou os mais de mil municípios do país não-operados pelas Cesbs, para os quais, depois da promulgação da Lei de Concessões, não havia mais impedimentos legais para privatizar seus serviços de saneamento. Bastava que o prefeito aprovasse um Projeto de Lei (PL) na Câmara Municipal para esse fim. 
Dentro desse universo de municípios, o Estado de São Paulo apresentava o conjunto potencialmente mais promissor de serviços municipais candidatos a serem privatizados, não apenas pelo grande número de população atendida (mais de 14 milhões de habitantes), mas também pela qualidade do desenvolvimento econômico dos municípios onde estavam instalados. Foi assim que em abril de 1995 a empresa multinacional francesa Suez-Lyonaise des Eaux, em consórcio com a brasileira CBPO, obteve a concessão para operar os serviços de saneamento da cidade de Limeira, próspero município da região de Campinas que parecia ser o primeiro de uma nova era de saneamento privado no Estado.

Ao analisar, porém, os resultados desse processo, passados quatro anos da promulgação da referida lei, observase que as privatizações completas de serviços não avançaram, mesmo com o empenho de muitos atores interessados, principalmente diversos prefeitos. Esse fato é intrigante, porque vários estudos demonstram os fortes recursos de poder dos Executivos, dentro do sistema político-partidário vigente (Limongi e Figueiredo, 1995). Eles possuem mecanismos institucionais e de barganha que lhes permitem, em geral, controlar as decisões dos legislativos e de quase todas as instâncias que poderiam ter algum tipo de poder de veto dentro do município. Mesmo assim, os prefeitos que tentaram uma privatização completa de suas redes de saneamento não conseguiram ultrapassar as instâncias que se interpuseram na consecução dos seus objetivos. A privatização em Limeira passou a ser, em São Paulo, uma exceção e não a regra. $O$ presente artigo evidenciará essa questão e tentará analisar quais as forças que se interpuseram ao poder dos prefeitos e como se organizaram para defender a gestão estatal do saneamento.

A primeira parte explica a composição do setor de saneamento dentro do marco político-institucional brasileiro, observando a predominância dos atores integrados ou ligados ao aparelho do Estado. Na segunda, as condições que propiciaram a entrada de um novo ator em busca de mercados: as empresas multinacionais. Na terceira parte, o campo da disputa, isto é, os municípios paulistas que tentaram privatizar seus serviços de saneamento e os argumentos utilizados para esse fim. Na quarta e última parte, o jogo entre os atores nas arenas institucionais, de influência e coercitivas em processos de privatização nos municípios de Limeira, Guarulhos e Jacareí, no Estado de São Paulo.

Por ser um estudo de caso, não será possível generalizar os resultados obtidos mas o trabalho pode contribuir para o entendimento, dentro de um estudo mais abrangente, das diversas modalidades de relacionamentos e conflitos entre o setor estatal da economia e o setor privado nos processos de privatizações.

\section{OS SETORES E O SETOR SANEAMENTO}

Quem se opõe à privatização de um serviço público? Quais são seus interesses? Como se mobiliza? Trabalhando com categorias olsonianas, Licínio Velasco Jr. (1997: 4041) nos oferece uma resposta bastante convincente a essas questões: "Os grupos de interesse, defensores do status $q u o$-administradores e associações dos funcionários das empresas, sindicatos de classe, ou companhias consumidoras ou fornecedoras -, se enquadram como as coalizões distributivas descritas por Olson (1982, cap. 1 a 3). Os beneficiários das empresas estatais são poucos e os benefícios percebidos são concentrados e significativos. Já os beneficiários mais imediatos da privatização são difíceis até de ser identificados. A sociedade aparece como a beneficiária, mas de forma difusa. Nesse sentido, a mobilização contra as privatizações, por parte dos grupos interessados na manutenção do status quo, tende a ser automática e com alto grau de coesão, o que se contrapõe à mobilização dos que apóiam ou que se beneficiam desta política".

A primeira impressão que fica do texto acima é a imediata força de mobilização dos atores contrários à privatização contra um adversário difuso. No entanto, os programas de privatização dos governos federal e estaduais foram levados muito adiante na década de 90 , o que significa que os beneficiários difusos tinham recursos de poder superiores, ou pelo menos souberam jogar com mais eficiência. Assim, o caso que veremos a seguir talvez seja uma exceção, ou talvez temporalmente não se sustente se houver mudanças nas correlações de forças, mas pode nos dar melhor compreensão de como se desenvolve esse jogo e como cada lado utiliza os recursos a seu alcance. Por outro lado, também levanta a questão das especificidades de cada setor, que não podem ser ignoradas nem desligadas do seu desenvolvimento histórico. Começaremos então definindo os atores ligados ao aparelho do Estado e a estruturação do setor de saneamento dentro do marco político-institucional brasileiro.

Segundo Pierre Muller, a intervenção pública se organiza sob duas lógicas: a territorial e a setorial, cada uma com racionalidade própria. No primeiro caso o sistema social a ser regulado compreende um entorno geográfico. 
No segundo, a intervenção pública procura regular a reprodução de uma entidade mais abstrata, constituída por um domínio de atividade construída verticalmente: os setores (Muller,1986:72), que podem ser entendidos como um conjunto de papéis sociais estruturados em uma lógica vertical e autônoma de atuação dentro da sociedade. É assim que vão se formar progressivamente novos espaços de reprodução (como os setores industriais, agrícolas, de saúde, de transportes e outros) de caráter a-territorial, conferindo aos indivíduos identidades profissionais. Nessa perspectiva, os setores aparecem como totalidades sociais que se organizam em objetivos específicos do ramo e tendem a transformar seus objetivos setoriais em fins últimos, ou seja, em interesse geral da sociedade. Por exemplo, "a lógica do setor da saúde vai no sentido de acrescentar indefinidamente as despesas com a saúde, 'porque a vida humana não tem preço"”; ou "a lógica das instituições militares vai no sentido de acrescentar sem limites as despesas com armamento, porque 'a segurança não tem preço'" (Muller, 1986:73). Em síntese, os setores representam a cristalização de uma identidade profissional, e não territorial, de grupos sociais.

Embora a setorialização das sociedades como modo de organização dominante seja um fenômeno típico do Estado moderno, ela se organiza dentro de marcos concretos de relações, que respondem aos particulares processos político-institucionais de formação e evolução dos Estados. Portanto, é importante entender brevemente como se insere o setor de saneamento dentro da sociedade brasileira. A intenção é mostrar o predomínio histórico dos atores que operam dentro do aparelho do Estado.

Segundo Eli Diniz (1995:34), o governo Vargas (193045), durante a construção do Estado moderno brasileiro, conferiu alta capacidade às elites estatais para controlar os recursos públicos. Concedeu à burocracia estatal não só um alto grau de autonomia na definição dos rumos do desenvolvimento, mas na delimitação dos próprios objetivos dos setores. Da mesma forma, Campelo de Souza (1976:86) mostra que essa autonomia burocrática não se deu por uma eficiência racional/formal segundo o paradigma weberiano das organizações burocráticas. A centralização burocrática varguista deveu-se a uma tática de absorção e cooptação dos agrupamentos de interesses, regionais e setoriais. Esse mecanismo permitiu a participação subordinada das elites empresariais na estrutura de poder, institucionalizando uma forma de negociação bipartite, que Diniz denomina "corporativismo setorial"
(1995:36), envolvendo empresários e burocratas (com exclusão dos trabalhadores) em políticas setoriais.

O saneamento não existiu como um verdadeiro "setor" até o final da década de 50 porque não possuía estrutura nem burocracia capacitada para desenvolver as funções de mediador setorial ${ }^{1}$ que possibilitasse absorver seu correspondente meio empresarial dentro do aparelho do Estado. Estruturou-se como tal no começo da década de 60, quando, decorrido algum tempo do processo de industrialização e urbanização, foi gerada a escala adequada para a realização de grandes investimentos e planejamento no abastecimento de água, que originou as grandes empresas estaduais de saneamento (as Cesbs), dentro das quais se integrou o componente privado.

Para a estruturação do setor, foi importante o advento do governo militar. Para a tecnocracia do regime, a falta de saneamento comprometia o objetivo de desenvolvimento econômico. Na ausência de capitais privados dispostos a investir na área, os investimentos públicos, com a criação de empresas estatais, foram considerados um requisito para promover a eficiência econômica e oferecer condições de infra-estrutura para o setor industrial. Buscou-se, no entanto, uma coerência global com os pressupostos tecnocráticos e centralizadores do regime, ou seja, foi elaborado um projeto para o saneamento, no qual se tentou alcançar uma racionalidade técnica na aplicação das verbas, baseado em um planejamento prévio e centralizado que se pretendia único e homogêneo para o território nacional.

Implementado de forma gradual, o projeto criou, em 1969, o Plano Nacional de Saneamento (Planasa), comandado pelo BNH e operado regionalmente pelas Cesbs, quase todas criadas com o plano. Embora de propriedade dos governos estaduais, as Cesbs eram subordinadas às diretrizes federais e deveriam obter a concessão dos serviços de saneamento dos municípios do seu Estado e operar em forma de monopólio. Esse fato gerou resistências de administrações municipais das cidades de médio e grande portes, principalmente nos Estados de Minas Gerais, Rio Grande do Sul e São Paulo, muitas das quais não aderiram ao Plano Federal e continuaram operando seus sistemas de saneamento de forma autônoma, mesmo abrindo mão dos recursos federais.

Com o modelo em referência, o saneamento se colocou entre os denominados "sistemas fechados", cuja principal característica era uma combinação de dominância do planejamento setorial da União e um arranjo tarifáriofinanceiro com funções redistributivas inter-regionais, e 
começou a se formar uma burocracia de elite dentro das empresas e a se consolidar uma capacitação nacional em engenharia e projetos. Também abriu um nicho para que as empreiteiras nacionais assumissem um papel de destaque nos grandes empreendimentos do setor.

Durante esse período, e para representar o conjunto dos interesses do setor, foi criada a Associação Brasileira de Engenharia Sanitária e Ambiental (Abes), integrada por funcionários técnicos das agências federais e das Cesbs, por fabricantes de materiais e equipamentos, por empresas de consultoria e empreiteiras de obras públicas. A Abes exerceu o monopólio de representação do setor até metade da década de 80 (Jorge, 1987:138). ${ }^{2}$

Enquanto existiu o regime militar, a simbiose Abes/ Cesbs em "anéis burocráticos" foi quase completa. Porém, nos últimos anos do regime, mudanças na ordem políticoeconômica conduziram ao aparecimento de diversas formas de participação à margem dessa estrutura corporativa setorial, esvaziando-a em sua capacidade de exercer o monopólio da representação de interesses (Diniz, 1995:38). Nessa linha, surgiram na década de 80 dois novos componentes organizados no setor: a Associação Nacional dos Serviços Municipais de Saneamento (Assemae) - formada principalmente pela alta burocracia dos serviços de saneamento dos municípios que não havia aderido às Cesbs - e sindicatos, em especial a Federação dos Trabalhadores Urbanitários (FNU). ${ }^{3}$ Embora os novos atores representassem interesses diferentes aos da Abes/Cesbs, divergindo em muitos aspectos, o consenso básico era que a prestação dos serviços de saneamento deveria ser operada diretamente por órgãos do Estado, inclusive dos fabricantes nacionais de equipamentos, materiais e empresas de engenharia que com o tempo aprenderam a lidar com os agentes públicos responsáveis pelos serviços. As principais divergências eram quanto ao nível apropriado de gestão, estadual ou municipal, e quanto à distribuição dos recursos federais.

Assim, o setor de saneamento entrou na década de 90 estruturado em uma conformação híbrida, ou seja, a coexistência da organização setorial tradicional da Abes/Cesbs (em São Paulo Abes/Sabesp) e os grupos mais vinculados aos municípios, principalmente a Assemae e a FNU. A partir de 1995, porém, com a ascensão de Fernando Henrique Cardoso à presidência e a promulgação da Lei de Concessões, um novo ator entra em cena para disputar o mercado de água com os atores ligados ao aparelho do Estado: as operadoras privadas, isto é, grandes empreiteiras e principalmente empresas multinacionais.

\section{A ENTRADA DE UM NOVO ATOR}

O desenvolvimento e a propriedade dos serviços de saneamento em quase todos os países do mundo estiveram historicamente nas mãos dos Estados, inclusive nos Estados Unidos, onde dos mais de 50 mil operadores existentes em 1995, apenas $15 \%$ eram privados. No fim da década de 80 , principalmente desde a privatização dos serviços de saneamento na Inglaterra, esse mercado começou a sofrer mudanças com a entrada de capitais privados na operação dos serviços. A abertura das barreiras nacionais no negócio da água colocou as empresas francesas Suez Lyonnaise des Eaux e Vivendi (ex-Générale des Eaux) como líderes mundiais. Elas dominaram o mercado porque aprenderam a lidar com suas características particulares: um mercado extremamente fragmentado e dirigido pelo poder público.

Embora a França seja um país com ampla tradição em serviços estatais, o abastecimento de água é uma das poucas exceções. Desde o começo, no século XIX, essa atividade esteve nas mãos da iniciativa privada. A Vivendi, por exemplo, obteve seu primeiro contrato municipal no começo do governo de Napoleón III, em 1853. A Lyonnaise, nessa época, também já existia. No modelo desenvolvido na França, os governos locais conservavam a propriedade da infra-estrutura enquanto as empresas privadas concorriam pelos contratos de gestão para oferecer o serviço. Esse modelo permitiu o aparecimento de empresas fortes e especializadas para lidar com um mercado fragmentado e público. Com o passar do tempo essas empresas aprenderam que uma das principais ferramentas para obter sucessos comerciais era cultivar relações estreitas com funcionários eleitos, e com eles criaram um forte lobby que ajudou a aventar as constantes ameaças de estatização dos serviços de água. Com essa grande experiência, as empresas francesas estavam em excelentes condições para oferecer seus serviços quando o mercado mundial se abriu no final década de 80 (Owen, Iskandar e Taylor, 1999).

Pouco depois, começaram a atuar na América Latina, obtendo concessões para operar em grandes cidades, como Buenos Aires, Santa Fé, Córdoba e Tucumán (Argentina), Valdivia (Chile), Bogotá (Colômbia) e na cidade do México, entre outras. Mas as francesas não foram as únicas. Entre as empresas multinacionais interessadas no mercado latino-americano estavam também as inglesas, North West Water e Thames Water, e a espanhola, Águas de Barcelona. A partir de 1995 essas empresas começam 
a operar no mercado brasileiro e em quase todas as tentativas de privatização de serviços de saneamento aparecem como as principais interessadas. ${ }^{4}$ Essas empresas, no entanto, não se limitam à operação de serviços de saneamento básico, mas atuam em vários ramos de serviços ambientais, incluindo as áreas de limpeza de ruas e disposição de resíduos industriais, entre outras. ${ }^{5}$ Também controlam, por meio de subsidiárias, fábricas de materiais e equipamentos. $\mathrm{O}$ interesse não se limita em obter concessões para operar serviços, mas visa criar um mercado cativo para suas próprias fábricas, verticalizando assim todo o ciclo produtivo. Isso explica a resistência dos empresários nacionais à privatização dos serviços.

A chegada das operadoras multinacionais teve o incentivo de setores do governo federal. Os operadores financeiros (BNDES e CEF) eram favoráveis a programas de reestruturação que implicassem a privatização tanto das Cesbs como de autarquias municipais. O BNDES, principalmente, atuou como um catalizador entre os agentes públicos dispostos a privatizar e os agentes privados dispostos a investir no saneamento mas, erroneamente, não associou esse processo com a adoção do marco regulatório, o que resultou, pelo menos até o ano 2000, um entrave para a privatização de empresas estaduais ${ }^{6}$ (Arretche, 1999:34), mas não dificultou a privatização pelas autarquias municipais, para as quais a Lei de Concessões era suficiente. Na realidade, a primeira experiência de gestão privada de serviços de saneamento no novo contexto foi em Limeira, nos primeiros meses de 1995, logo acompanhada por várias outras tentativas. A seguir, vejamos o que aconteceu em São Paulo.

\section{O CAMPO DA DISPUTA}

Embora existissem em 1995, no Estado de São Paulo, 625 municípios, a privatização dos serviços de saneamento estava limitada por dois condicionantes. O primeiro devese à existência, no Estado, da Sabesp. O prefeito de um município concedente dessa empresa, para poder privatizar, deve primeiro rescindir o contrato de concessão, o que é legalmente muito complexo (Sanchez, 2000:35). Esse fato limitou os prováveis candidatos a 295 municípios, dos 625 existentes no Estado, pois a Sabesp operava em 330. O segundo condicionante é o fator "escala econômica". Realmente, os serviços de saneamento básico são monopólios naturais, serviços de utilidade pública em que a existência de mais de um produtor mostra-se anti-econômica. A lógica é a redução dos custos pelo aumento da escala de produção permitindo a prestação do serviço com tarifas mais baixas que em regime de concorrência. O problema, quando o monopólio é privado, é atingir uma produção em escala necessária para equilibrar as tarifas acessíveis, o retorno dos investimentos e a geração de lucros, sem considerar os subsídios estatais. E essa condição não tornaria viável a privatização completa de serviços de saneamento em municípios com população abaixo de $50 \mathrm{mil}$ habitantes. ${ }^{7}$ Mesmo assim, de 295 municípios em condições legais de privatizar seus serviços de saneamento, ainda teríamos 54 com a escala econômica apropriada. E é nesses que nos deteremos.

O processo de privatização normalmente começa com a chegada ao município de representantes das operadoras privadas, que a partir de 1995 adotaram uma agressiva política de assédio às autoridades locais tentando mostrar as vantagens de privatizar o saneamento das suas cidades. Essas empresas, a pedido ou não do prefeito, procuram informações técnicas nos DAAEs ou SAAEs, ${ }^{8}$ elaboram um estudo de viabilidade para a concessão (total ou parcial) dos serviços e o apresentam ao prefeito, formal ou informalmente, que avalia se é conveniente a concessão. Em caso positivo, contrata uma empresa de consultoria para elaborar o edital e a seguir envia um PL à Câmara Municipal. Se aprovado o PL (o que nem sempre acontece), o prefeito publica o edital e mais tarde é feita a licitação pública. Mesmo depois de realizada a licitação, a qual normalmente enfrenta contestações judiciais de sindicatos, associações ou de empresas que se sentiram prejudicadas, esta pode ser cancelada (mais adiante veremos por quê). Esse processo se repetiu, em suas diferentes formas, em todos os municípios onde se tentou privatizar.

Ao serem examinadas as "tentativas" de privatização, isto é, a vontade política de um prefeito em privatizar o saneamento de sua cidade - considera-se vontade efetiva apenas quando é enviado um PL à Câmara Municipal pedindo autorização -, devem-se observar quais foram os municípios que tentaram privatizar, o resultado da votação do PL e se a concessão foi efetivada.

Nove prefeitos enviaram PLs às Câmaras Municipais para privatizar seus serviços de saneamento mas apenas quatro foram aprovados e os cinco restantes, rejeitados (ou retirados pelo prefeito antes da votação). ${ }^{9}$ Mesmo assim, apenas um processo foi concretizado, o de Limeira.

Um dos principais argumentos de defesa da entrada da iniciativa privada na operação de serviços municipais de saneamento era que a empresa faria os investimentos ne- 
TABELA 1

Municípios que Tentaram a Privatização Completa de seus

Sistemas de Saneamento

Estado de São Paulo - 1995/98

\begin{tabular}{lllc}
\hline Municípios & $\begin{array}{c}\text { Partido do } \\
\text { Prefeito }\end{array}$ & $\begin{array}{c}\text { Projeto de Lei na } \\
\text { Câmara Municipal }\end{array}$ & $\begin{array}{c}\text { Privatização } \\
\text { Efetivada }\end{array}$ \\
\hline Limeira & PMDB & Aprovado & Sim \\
Jacareí & PMDB & Aprovado & Não \\
Guarulhos & PMDB & Aprovado & Não \\
Leme & PFL & Aprovado & Não \\
Catanduva & PMDB & Rejeitado & Não \\
Indaiatuba & PMDB & Rejeitado & Não \\
Valinhos & PMDB & Rejeitado & Não \\
Matão & PT & Rejeitado & Não \\
Rio Claro & PPB & Rejeitado & Não \\
\end{tabular}

Fonte: Jornal da Assemae; TRE.

cessários para permitir o aumento dos índices de coberturas das redes de água e esgotos existentes, porque havia falta de recursos dos órgãos públicos gestores dos sistemas (Moreira, 1996 e 1998; BNDES, 1998). Esse argumento, porém, não é generalizável. Dos 54 municípios do Estado com sistemas municipais e mais de 50 mil habitantes, 47 apresentavam um índice de cobertura de abastecimento de água superior a $90 \%$, e em 43 a cobertura de esgotos canalizados era superior a $75 \%$ já em 1991 . Os índices de cobertura de $90 \%$ e $75 \%$ para água e esgoto são respectivamente os mínimos recomendados pela ONU para atender às populações urbanas. ${ }^{10}$ Dos sete sistemas municipais com cobertura deficientes, cinco deles - Campo Limpo Paulista, Várzea Paulista, Itararé, Hortolândia e Mogi das Cruzes - outorgaram a concessão dos seus serviços à Sabesp nos anos de 1997/98, o de Mogi das Cruzes de forma parcial. Ou seja, com exceção de Guarulhos e Atibaia, os sistemas municipais autônomos restantes de São Paulo possuem bons (ou muito bons) índices de cobertura de redes de água e esgoto. Esse não foi, portanto, um motivo relevante que justificasse as tentativas de privatização.

Por exemplo, no edital de privatização no município de Jacareí se estipulava que as coberturas deveriam chegar, nos primeiros cinco anos de concessão, a $98 \%$ as de água, e a $91 \%$ as de esgoto, mas já existiam coberturas de 95\% e 90\%. Em Limeira, Catanduva e Leme os editais previam a universalização em cinco anos, e as coberturas já eram de $98 \%$ e $93 \%$ em Limeira; $99 \%$ e $96 \%$ em Catanduva, e $99 \%$ e $95 \%$ em Leme, segundo dados do
IBGE de 1991. Na verdade, e dentro dessa lógica, esse seria um argumento válido para privatizar apenas no município de Guarulhos, onde as coberturas eram de $86 \%$ e $52 \%$, porém nesse município o edital de privatização não previa coberturas a alcançar.

Por outro lado, salvo exceções, como o município de Matão, as autarquias de São Paulo são superavitárias ou se auto-sustentam sem recorrer a recursos orçamentários, mesmo considerando em alguns casos o excesso de funcionários ${ }^{11} \mathrm{e}$ as tarifas subsidiadas para moradores na faixa de consumo de até 10 metros cúbicos, praticadas por quase todos os sistemas municipais. Isso significa que os serviços de água, como regra, são rentáveis.

Pode-se supor que o principal interesse dos prefeitos em privatizar os serviços seria a remuneração que as empresas privadas pagariam ao município pela concessão. É necessário, porém, observar que a concessão em saneamento é do tipo "não-onerosa", ou seja, a empresa ganhadora não paga ao município pela concessão, apenas se compromete a investir na melhoria dos serviços. Não há, praticamente no mundo inteiro, concessões onerosas porque o objetivo básico de uma mudança de gestão nesse setor é a universalização dos serviços não apenas para o conforto da população, mas, e principalmente, como instrumento preventivo de saúde pública. ${ }^{12}$

Por fim, não existiam serviços altamente endividados, porque as autarquias municipais não têm grande capacidade de endividamento. Os recursos para investimentos e/ou capacitação técnica são da própria autarquia ou orçamentários do município. Eventualmente obtêm recursos na CEF ou de programas estaduais, como o Sanebase e o Fehidro. ${ }^{13}$ Nessas condições, torna-se evidente o legítimo interesse das empresas privadas: altas coberturas já instaladas, serviços rentáveis, concessões não-onerosas, recursos para investimentos do BNDES. Mas, vistos de outro ângulo, quais foram os argumentos utilizados pelos prefeitos? Se um prefeito realmente quiser privatizar, uma boa empresa de consultoria pode elaborar argumentos que justifiquem tal alternativa, como por exemplo em Jacareí, onde se argumentou que existiria uma forte demanda de água para consumo industrial. Ademais, como nenhum serviço possui um funcionamento perfeito, determinados aspectos técnicos, operacionais e a previsão de objetivos empresariais a serem alcançados podem ser elementos importantes para uma razoável justificativa. Dessa forma, o prefeito tendo decidido privatizar os serviços, começa o jogo na arena institucional, na qual vai tentar se valer dos recursos de poder que seu papel lhe confere. 


\section{O JOGO}

Quando um prefeito tenta dar a concessão de seus serviços de saneamento, são duas as alternativas: ou opta por empresas privadas ou pela Sabesp. Como a empresa estadual não participa de concorrências públicas, ${ }^{14}$ a opção do prefeito deve ser feita antes de enviar o PL à Câmara Municipal. Não há disputa direta nas concorrências entre a Sabesp e as empresas privadas. A opção entre uma e outra deve ser do prefeito. Qualquer que seja a opção, a resistência à concessão começa na Câmara Municipal embora em menor medida quando a escolhida é a Sabesp - no momento do envio do PL pelo prefeito, que precisa ser aprovado por maioria qualificada.

Para a aprovação do projeto, o prefeito conta sempre com o apoio "fechado" de seu "grupo", que não necessariamente se confunde com sua base de sustentação na Câmara Municipal, da qual é apenas uma parte. Como é necessário um amplo número de votos para aprovar o PL, a capacidade e os meios disponíveis de ambas as partes (por um lado, o "grupo" do prefeito, e por outro, a oposição) para convencer os vereadores do grupo intermediário - que normalmente votam com o prefeito mas que não são de seu "grupo" - decidirão o resultado. Se o prefeito não consegue convencer um número suficiente de vereadores, retira o projeto.

A principal resistência ao PL surge dos vereadores que fazem oposição sistemática ao prefeito, mas essa resistência não pode ser interpretada em função da condição ideológico-partidária dos vereadores sobre o papel do Estado na provisão de bens e serviços. Em Indaiatuba, por exemplo, a oposição ao projeto de privatização do prefeito do PMDB, Flavio Tonin, foi liderada pelo vereador eleito pelo PFL, Tadao Toyama. Em Matão, a principal oposição ao projeto do prefeito do PT, Adauto Scardoelli, foi do vereador do PMDB, Edson Correia. Em Limeira, a oposição ao projeto do prefeito do PMDB, Jurandir Paixão, foi de Luiz Carlos Pierre, do PT, junto com Davi Poleti, do PFL. No entanto, a disputa na Câmara Municipal pela aprovação do PL não fica circunscrita a esse espaço. Existem fontes de pressão externa sobre os vereadores do grupo intermediário para votar contra: a primeira se dá pelos sindicatos dos trabalhadores do DAAE/SAAE em questão; a segunda, promovida pela ação da Assemae e, em algumas situações, também da Sabesp. Nesse momento não há divergências entre os atores do setor. Pelos fortes recursos de poder do prefeito, o interesse comum é dominar principalmente a arena de influência, isto é, o espaço em que os grupos e indivíduos disputam o domínio sobre a opinião pública e no qual cada um busca moldar as concepções sociais sobre os assuntos em pauta.

O grupo de vereadores de oposição normalmente não tem os conhecimentos técnicos necessários para questionar as necessidades que o prefeito, amparado por uma consultoria prévia, justifica para privatizar os serviços. Nesse sentido, a ação desses vereadores poderia parecer uma pura oposição destrutiva ao projeto do prefeito. Tampouco o conhecimento vem dos sindicatos, que possuem alguma capacidade (de acordo com o município) para mobilizar determinados grupos sociais, principalmente os ligados à igreja católica e outros sindicatos, a pressionar os vereadores. Em geral não possuem propostas concretas, a não ser as de cunho ideológico (o saneamento deve ser uma "função do Estado"), mas que pode ser confundida apenas com interesse corporativo. A ação técnica e o conhecimento que vão fundamentar a oposição e refinar a posição dos atores locais dando-lhes as bases para consolidar um movimento coerente de opinião pública, contrário à privatização, são da Assemae.

Nas audiências públicas que precedem a votação do projeto (em geral presentes os formadores de opinião da cidade: jornalistas, engenheiros, padres, professores, e outros - lembrando que não se está lidando com megacidades, como Rio de Janeiro ou São Paulo e a ação dessas pessoas é extremamente capilar), a Assemae manda sua "tropa de choque", formada por um pequeno grupo de assessores técnicos e jurídicos capacitados para enfrentar o prefeito e as empresas de consultoria em que ele se apóia no campo do conhecimento.

Depois de expor um diagnóstico da situação do SAAE/ DAAE em questão, a Assemae invariavelmente apresenta projetos concretos para solucionar os eventuais problemas, tanto de questões técnicas como administrativas e/ ou financeiras. A capacidade de seus representantes para tornar compreensível uma questão de natureza complexa, inclusive discutir os aspectos obscuros (para os leigos) dos editais de concessão, dificulta a defesa dos argumentos em favor das privatizações. Por outro lado, expõe, por exemplos internacionais e principalmente com o caso "Limeira", que uma privatização é seguida de um aumento de tarifas. E esse é um elemento de influência muito importante, porque quando os serviços de saneamento são deficientes, principalmente quando falta água nos domicílios, qualquer solução proposta para o problema, inclusive um aumento de tarifas ou até a privatização dos serviços, pode ser aceitável para a população. No entanto, 
como os problemas de abastecimento de água e coleta de esgotos no Estado de São Paulo não são graves, ao contrário, os sistemas municipais possuem em geral boas coberturas, a ameaça de "aumento tarifário" (real ou imaginário) torna-se um elemento de pressão muito forte, depois de eficientemente divulgado.

A seguir, e convencidos desses argumentos, jornais, emissoras de rádio do município, movimentos populares $\mathrm{e}$, em alguns lugares, a igreja católica, ${ }^{15}$ entram na campanha de pressão sobre os vereadores já em posse de elementos concretos para sustentar uma discussão fundamentada. Ou seja, o papel da Assemae não é apenas um trabalho de reflexão técnica e de elaboração de propostas de novas medidas de intervenção. Seu principal papel no município é transformar uma realidade relativamente obscura em um programa de ação política coerente, fornecendo as ferramentas necessárias para superar a assimetria de informação. Essa pressão sobre os vereadores, facilitada pela necessidade de se obter maioria qualificada para aprovar o projeto de lei, fez os prefeitos desistirem da privatização em cinco dos nove municípios em questão, embora em alguns, como Rio Claro, nem foi necessária a ação "institucional" da Assemae, mas apenas dos membros dessa organização atuantes no próprio município. Em síntese, dominar a arena de influência como fator de pressão sobre os vereadores tornou-se a primeira e grande instância de veto às privatizações.

Em quatro municípios, no entanto, os recursos de poder dos prefeitos mostraram-se superiores às pressões externas e conseguiram aprovar o PL: Limeira, Jacareí, Guarulhos e Leme. Assim, a luta do setor continua fora da Câmara Municipal, na arena institucional, principalmente com ações na justiça. Aqui a oposição foi em certa medida facilitada por suspeitas de concorrências dirigidas com a manipulação dos editais. A experiência adquirida pela privatização em Limeira possibilitou à Assemae munir os sindicatos e outras organizações com os meios necessários para a batalha judicial. Por outro lado, houve a intervenção da Sabesp atuando também na arena coercitiva, que pelo seu impacto foi capaz, na sua área de influência, de constranger os agentes da privatização. Vejamos o que aconteceu nos municípios de Limeira, Guarulhos e Jacareí.

\section{Limeira}

Em 1994, o prefeito de Limeira, Jurandir Paixão (PMDB), contratou a empresa de consultoria Socienco, sob o critério de notória especialização, para fazer um estudo de viabilidade a fim de outorgar a concessão do sistema de saneamento da cidade ao setor privado.

O processo de concessão começou na quarta-feira, 27 de abril de 1994, quando o prefeito enviou um PL à Câmara Municipal em regime de "urgência especial". Como a Câmara se reunia apenas às segundas-feiras, foi convocada uma reunião extraordinária para sexta-feira, dia 29. O projeto, sem passar por nenhuma comissão temática, foi direto para o relator que, em poucas horas, deu parecer favorável. Convocada uma nova reunião extraordinária para o domingo, foram apresentadas 30 emendas, mas a bancada ligada ao prefeito rejeitou todas e aprovou o projeto original por 15 votos a 6 . Poucos dias depois (em maio desse ano) foi lançado o edital. Uma das exigências era as empresas concorrentes já terem operado sistemas de saneamento em cidades com pelo menos 10 mil domicílios (aproximadamente 40 mil habitantes). Como não existiam no Brasil empresas privadas que cumprissem tal requisito, a vencedora deveria estar assim obrigatoriamente coligada a uma operadora estrangeira. Porém, uma empresa nacional interessada, a Buzolin, entrou na justiça e conseguiu suspender a concessão questionando as exigências do edital.

No ano seguinte, em 1995, já na vigência da Lei de Concessões, foi feito um novo edital e a licitação realizada no mês de abril, quando a classificação final das empresas participantes e suas propostas não foram apresentadas, apenas foi declarado vencedor, como já se esperava na cidade, o consórcio formado pelas empresas CBPO (do Grupo Odebrecht) e a francesa Suez Lyonnaise des Eaux, que assumiu a operação dos serviços dois meses depois com o nome de Águas de Limeira. A concessão foi nãoonerosa, pelo prazo de 30 anos, e a nova empresa se comprometeu a investir R \$ 98 milhões, dos quais $40 \%$ nos cinco primeiros anos.

Nos primeiros meses de concessão, as tarifas aumentaram em parte pelo repasse do ISS que não era cobrado anteriormente. Também a cota mínima de consumo subsidiado baixou de 10 para 5 metros cúbicos. Seguiram-se inúmeras denúncias sobre a queda da qualidade do serviço, noticiadas quase diariamente na imprensa local e regional. A Câmara Municipal instaurou pouco depois uma CPI para investigar a privatização. As suspeitas eram de irregularidades no edital, indícios de enriquecimento ilícito do prefeito e o fato de a empresa de consultoria contratada antes da privatização ter vínculos empresariais com o Grupo Odebrecht, uma das ganhadoras da concessão. 
Depois de três meses de investigações, a CPI apresentou como resultado dois relatórios, um do grupo de oposição ao prefeito e outro do grupo que o apoiava. Este último foi considerado oficial e não apontou irregularidades.

No ano seguinte, o Ministério Público (MP) impetrou uma ação civil solicitando a anulação da concessão. A ação foi deferida na $4^{\text {a }}$ Vara de Justiça da cidade. Também o MP solicitou uma ação cautelar requerendo o seqüestro dos bens do prefeito, acusado de fraude e enriquecimento ilícito, porém indeferida porque o juiz considerou as provas inconsistentes. Nesse mesmo ano, o Tribunal de Contas do Estado (TCE) apontou "graves" irregularidades no processo. ${ }^{16}$ Essa foi, até dezembro de 1998, a única concessão total efetivada em municípios com população superior a 50 mil habitantes no Estado de São Paulo. ${ }^{17}$

Em Limeira houve mobilização política, principalmente de partidos opositores ao prefeito, mas Jurandir Paixão conseguiu ultrapassar todas as instâncias adversas e levou adiante a privatização. Deve-se observar, no entanto, que ela começou formalmente em 1994 e concretizou-se nos primeiros meses de 1995. Tanto a Sabesp, que estava se reestruturando e definindo sua política nesse período, como a Assemae ainda não estavam preparadas para agir contra adversários desse porte.

O processo vitorioso em Limeira foi um forte impulso para as empresas privadas, principalmente as francesas, tentarem entrar no Estado de São Paulo. Mas por outro lado proporcionou ao "setor" saneamento um aprendizado que utilizaria com muita competência nas posteriores tentativas de concessão, principalmente em sua função estratégica para influir nos municípios, além de capacidade para enfrentar suspeitas de manipulação de licitações. Limeira foi na realidade uma "vitória de Pirro" para a Lyonnaise des Eaux em São Paulo. Ficou com má-fama no Estado.

\section{Guarulhos}

Observando a forma de atuação da Lyonnaise em Limeira, assim como nos processos de concessão nos quais a empresa esteve envolvida nas cidades de Mendoza e Córdoba, na Argentina, ela parece seguir, pelo menos na AméricaLatina, um determinado padrão. Dificilmente a empresa entra em uma concorrência sem ter algum tipo de acordo prévio com as autoridades que comandam o processo. ${ }^{18}$ Vejamos o que aconteceu no município de Guarulhos.

Depois de obter a concessão em Limeira, a empresa francesa apostou na concessão do maior município do
Estado de São Paulo (com exceção da capital). Em Guarulhos, localizado na Região Metropolitana, o prefeito Vicentino Papotto (PMDB) enviou, em maio de 1996, um PL à Câmara Municipal pedindo autorização para conceder à iniciativa privada a gestão completa dos serviços de água e esgotos.

Um parecer feito por uma empresa de consultoria contratada pelo prefeito apontava a concessão como uma resposta à falta de água em alguns bairros, uma vez que o município comprava água por atacado da Sabesp e não era suficientemente abastecido por ela. A provável concessionária, ademais, deveria buscar fontes alternativas de captação para diminuir essa dependência. Outra solução apontada era a resolução de deficiência de cobertura das redes de esgoto, que nesse ano alcançava pouco mais de $50 \%$ dos domicílios, a pior da RMSP.

O PL foi aprovado na Câmara Municipal em 13 de junho de 1996 por 18 votos a 3. No entanto, a votação foi anulada pela justiça porque não foi permitida a apresentação de emendas ao projeto, contrariando o regimento interno da casa. A segunda votação aconteceu no dia 16 de agosto e o projeto voltou a ser aprovado pelo mesmo placar (18 a 3). Assim como em Limeira, todas as emendas apresentadas foram indeferidas. No dia 3 de setembro, o SAAE publicou um aviso para que as empresas interessadas retirassem o edital e marcou-se para o dia 23 de outubro a data de abertura dos envelopes. Os principais concorrentes à concessão eram as francesas Lyonnaise des Eaux e Vivendi. Também como em Limeira, a imprensa local noticiava antecipadamente que a Lyonnaise seria a vencedora da concorrência.

Durante o período de tramitação do projeto de lei aconteceram audiências públicas na Câmara Municipal e em uma universidade da região, e foram chamadas a participar a Sabesp e a Assemae. As complexidades da operação do SAAE e das regras técnicas do edital demandaram a presença de pessoas do setor. ${ }^{19}$ Os representantes da Assemae, fazendo um diagnóstico sobre a situação do SAAE, mostraram que o principal problema era operacional. Existiam deficiências na cobertura de esgotos, mas os investimentos necessários reduziam-se a redes coletoras domiciliares. Segundo a Assemae, o município não precisava investir no tratamento nem na disposição final porque Guarulhos era um sistema complementar ao operado pela Sabesp em toda a RMSP. Quanto à falta de água, o SAAE tinha perdas (físicas e principalmente de fraudes na leitura de hidrômetros) de mais de $40 \%$. O fato de maior impacto sobre a população e a mídia local, no entanto, foi 
mostrar os aumentos de tarifas e a suposta queda de qualidade dos serviços que ocorreu no município de Limeira depois de a Lyonnaise ter assumido os serviços.

Por outro lado, a Sabesp, interessada em operar no município, se propôs a assumir a concessão, comprometendo-se a alcançar, em cinco anos, $100 \%$ de cobertura das redes de água e $85 \%$ das de esgotos, que nesse momento eram de $86 \%$ e apenas $52 \%$, respectivamente. Para chegar a esse resultado, a empresa calculava investir $\mathrm{R} \$ 180$ milhões, mas o prefeito alegou que pelo estudo da empresa de consultoria por ele contratada seriam necessários investimentos da ordem de R $\$ 780$ milhões e que outras empresas estavam dispostas a investir esse valor. Considerando a licitação de cartas marcadas, o vice-presidente da Sabesp, Antônio Marsiglia Neto, declarou em audiência pública que a água fornecida pela Sabesp ao município era subsidiada e ameaçou cortar o subsídio caso o SAAE fosse transferido a uma operadora privada, o que causaria um brusco aumento de tarifas. Além disso, a empresa não se comprometeria em abastecer de água suficiente esse município, porque daria prioridade a outros municípios da região, de gestão pública (Jornal da Assemae, jun. 1996:11).

Com o material debatido nessas audiências - e principalmente com as ameaças da Sabesp - os jornais e as emissoras de rádio do município começaram a fazer uma campanha contrária à privatização, enfatizando principalmente um inevitável aumento de tarifas numa gestão privada e as suspeitas de que a concorrência era manipulada. Em pleno período eleitoral, o prefeito Vicentino Papotto percebeu que esse movimento estava prejudicando seu candidato, Pascoal Thomeu. Para não sofrer prejuízos eleitorais, acabou enviando um novo PL à Câmara no dia 23 de outubro, cancelando a concessão.

No entanto, pouco antes de o prefeito cancelar a concessão, dirigentes da Lyonnaise procuraram a Sabesp para negociar regras claras para uma futura compra de água por atacado. Não é possível provar a resposta dos dirigentes da Sabesp mas é possível inferir que, por ter também interesse na concessão, sua resposta fosse negativa. Alguns dias depois, ao cancelar a concessão, o prefeito justificou sua atitude alegando que o processo de privatização "está sendo explorado politicamente e poderá trazer prejuízos irreversíveis ao município na medida em que afasta licitantes em potencial" (grifos meus) (Jornal da Assemae, out. 1996:10). As empresas se retiraram da disputa pela falta de garantias da Sabesp no fornecimento de água.
Concluindo, na tentativa de privatização em Guarulhos, embora o papel da Assemae na assessoria aos vereadores e aos sindicatos tenha sido importante para dar bases concretas à mobilização contrária à privatização, o poder de coerção da Sabesp teve também um papel relevante. No cálculo da empresa, o importante era não deixar as francesas ganharem. Mantendo a gestão com a prefeitura, poderia obter a concessão com os próximos prefeitos.

\section{Jacareí}

A participação do setor também pode ser constatada na tentativa de privatização no município de Jacareí. Nesse município, em janeiro de 1996, o prefeito Thelmo Cruz (PMDB) enviou um PL à Câmara Municipal pedindo autorização para outorgar a concessão total dos serviços de saneamento do município prestado pelo SAAE. O prefeito justificou o pedido alegando falta de condições financeiras para ampliar o consumo industrial e construir estações de tratamento de esgotos. O município possui 173 mil habitantes e está situado na região de São José dos Campos. O SAAE nesse ano abastecia de água $95 \%$ dos domicílios e $90 \%$ possuíam rede de esgotos, mas não existia tratamento. A consultoria prévia e a preparação do edital foram realizadas por pessoas ligadas à Fundação Escola de Sociologia e Política de São Paulo. ${ }^{20}$ Os próprios representantes dessa Fundação foram os encarregados de defender a privatização nas audiências públicas.

Nos primeiros dias de março desse ano, o PL foi aprovado na Câmara Municipal, mas (novamente) por problemas regimentais houve uma segunda votação, quando o prefeito obteve outra vitória. Entretanto, apenas em outubro o edital foi lançado, marcando para o dia 5 de dezembro a abertura dos envelopes, menos de um mês antes da mudança de prefeito.

O movimento de oposição no município apresentou características similares às de Guarulhos. Começou com a mobilização de alguns vereadores de oposição e o sindicato dos trabalhadores do SAAE/Jacareí, recebendo ajuda da Assemae e da Sabesp para a luta travada na arena de influência.

Além de participar das audiências públicas, nas quais municiou a imprensa local com elementos concretos sobre os problemas de privatizar os serviços, a Assemae prestou assessoria jurídica ao sindicato para que ele entrasse com uma ação popular na justiça contra a privatização. Já a Sabesp - que nesse município não tinha poder coercitivo como em Guarulhos - novamente se apresen- 
tou como "alternativa", recusada pelo prefeito com a alegação de que a Lei de Concessões exigia uma licitação pública. A empresa entrou então com um mandado de segurança na justiça alegando que o edital feria a Lei de Licitações. Ao mesmo tempo, a empresa Estacon Engenharia entrou com um pedido de impugnação do edital no Tribunal de Contas do Estado. ${ }^{21}$

Nos primeiros dias de dezembro, o juiz da primeira vara do Fórum de Jacareí, concedeu liminar suspendendo a concessão com base na ação popular promovida pelo Sindicato dos Trabalhadores do SAAE (e elaborada pela Assemae). O juiz acatou a tese de que o edital de concessão feria a Lei de Licitações "ao restringir a participação de empresas". Em janeiro do ano seguinte o novo prefeito, Benedicto Lencini (PSDB), enviou um PL à Câmara Municipal cancelando a privatização.

A partir de 1997, com a ascensão dos novos prefeitos, as tentativas de privatização praticamente cessaram, com exceção de Matão, que foi abortada pela atuação conjunta da Assemae e dos sindicatos. Nesse município, a proposta da Assemae de tornar viáveis os serviços de saneamento (que eram deficitários) acabou sendo adotada e implementada pelo prefeito.

\section{CONCLUSÃ̃O}

A opção por privatizar serviços de saneamento municipais no Estado de São Paulo foi limitada por alguns fatores condicionantes. No primeiro, de ordem legal, os municípios concedentes da Sabesp eram ligados à empresa por contratos assinados nas décadas de 70 e 80 , pelo período de 30 anos, com cláusulas que dificultavam a rescisão e privilegiavam a própria Sabesp na hora da sua renovação. No segundo, de ordem estrutural, a operação privada era potencialmente viável em municípios que apresentavam escala econômica de produção. Isso limitou a 54 os que cumpriam esses requisitos. Observa-se, no entanto, dentro desse universo, que quando se tentou uma privatização total dos serviços existiu um terceiro condicionante, um fator político, isto é, uma forte e organizada resistência de diversos atores sociais agrupados no chamado "setor" saneamento. Formado no Estado basicamente pela Sabesp, pela Assemae e por sindicatos, esse setor, embora representasse interesses muitas vezes divergentes, reuniu o que cada um tinha de mais forte para defender seu mercado.

O número de 54 municípios é expressivo em um país onde predominam as Cesbs. Esse fato em grande parte foi produto das políticas prévias ao Planasa em São Paulo, que criaram as condições para que eles resistissem em se incorporar à Sabesp durante o período autoritário (Sanchez, 2000:25-28). Como resultado, formou-se uma burocracia municipal que aprendeu com o tempo a lidar com carências administrativas e de recursos. No período da re-democratização criou-se a Assemae, que tem em São Paulo sua principal base.

Durante as tentativas de privatização, a Assemae aportou o conhecimento técnico que ajudou a combater a assimetria de informação, possibilitando ao setor político das cidades, à mídia, aos movimentos sociais e, principalmente, aos sindicatos, meios para organizar movimentos de resistência coerentes na luta para dominar, sobretudo, a arena de influência. Já os sindicatos mostraram um poder de mobilização expressivo quando municiados de meios efetivos para agir.

A existência no Estado de uma Cesb, como a Sabesp, não é um impedimento per se à entrada do setor privado. $\mathrm{O}$ fato significativo é que a Sabesp implementou durante o período em questão uma política empresarial com o objetivo de tornar a empresa mais eficiente e expandir sua área de atuação dentro do Estado. Assim, atuou, por um lado, como força intimidatória. Se houve apenas nove prefeitos que tentaram formalmente uma privatização completa de seus serviços de saneamento, em grande parte foi resultado da política expansiva da empresa no Estado. Ou seja, qualquer prefeito que tenta uma concessão dos serviços deve antes construir fortes argumentos para responder à pergunta: por que outorgar a empresas privadas e não à Sabesp? Por outro lado, obstruída de participar de concorrências, criou regras informais no jogo ao ameaçar cortar subsídios em Guarulhos. Dentro de sua principal área de influência, a RMSP, a Sabesp, um ator interessado em condições privilegiadas, tornou as regras formais menos decisivas, em virtude de seu alto poder coercitivo.

A resistência foi facilitada por aspectos institucionais/ legais como, por exemplo, a necessidade de maioria qualificada nas Câmaras Municipais para aprovar os projetos de privatização. No entanto, a experiência de Limeira mostrou que os impedimentos poderiam ser ultrapassados - com os fortes recursos de poder dos prefeitos - se não encontrassem pela frente uma resistência coesa. Por outro lado, as ações das agências federais no período, principalmente do BNDES - indutor da privatização dos serviços - pecaram por não considerar as especificidades qualitativas e institucionais de cada Estado. Ou melhor, o que pode ser bom para um Estado não será necessaria- 
mente para todos os outros. Em São Paulo, o cruzamento dessas condições e a indução à privatização de um serviço público razoavelmente eficiente tornaram necessário criar "incentivos" que extrapolaram uma legítima e honesta busca por mercados.

\section{NOTAS}

E-mail do autor: oscar9san@hotmail.com

Agradeço a colaboração e comentários da professora Maria Herminia Tavares de Almeida e a ajuda da Fapesp.

1. Os mediadores setoriais são os agentes do setor com capacidade e visão de conjunto para elaborar políticas públicas (Pierre Muller, 1986).

2. Antes da criação da Abes, os engenheiros sanitários se reuniam na Associação Interamericana de Engenharia Sanitária (Aidis), criada em 1946. A seção brasileira da Aidis foi fundada no Rio de Janeiro em 1948 e a de São Paulo, em 1949. Durante esse período, além dos prestadores de serviços municipais e estaduais, existiam 13 agências federais que lidavam com saneamento básico, embora de forma não-exclusiva, como a Sudene, o DNOS e o DNOCS, e tinham modelos de gestão e interesses diferentes. A partir do Planasa, as Cesbs praticamente monopolizaram a prestação dos serviços.

3. A Assemae congrega advogados, administradores de empresa e principalmente engenheiros sanitários. Foi fundada em 1984 por iniciativa de sanitaristas da Fundação Nacional de Saúde (Funasa), autarquia do Governo Federal, para defender os interesses dos municípios não-concedentes das Cesbs. Embora conte com associados em todo o país, a principal base da Assemae está no Estado de São Paulo. Já a FNU tem base nacional, congrega 62 sindicatos, reúne trabalhadores dos setores de energia elétrica, gás e saneamento e nesses setores atua por meio de sua Secretaria de Saneamento.

4. Por exemplo, a Vivendi controla, desde 1997, 38\% da Cesb do Paraná, a Sanepar. Ademais, na tentativa de privatização (não-concretizada) da Cesb do Rio de Janeiro, a Cedae, o provável consórcio vencedor seria formado pela Vivendi, com $40 \%$, Lyonnaise des Eaux, também com $40 \%$, e Thames Water, com $20 \%$. A primeira capital de Estado a privatizar os serviços de água foi Manaus, em março do ano 2000. A empresa vencedora foi a Lyonnaise.

5. A empresa Vega Engenharia, por exemplo, que presta serviços de recolhimento de lixo e limpeza de rua para a Prefeitura de São Paulo, pertence à Lyonnaise des Eaux. No ano de 1998, a empresa convidou o prefeito Celso Pitta para visitar sua sede na França, pagando todas as despesas (segundo denúncia da jornalista Rosely Forganes, da Rádio Eldorado). Pouco depois de sua volta da França, o prefeito denunciou a falta de contrato de concessão do Município com a Sabesp e se propôs a entrar na justiça para recuperar a concessão dos serviços para posteriormente privatizá-los. Quem comandaria o processo seria o ex-senador pelo Amazonas Gilberto Miranda, que tem ligações comerciais com a Lyonnaise, mas a iniciativa não avançou. De qualquer forma, o Ministério da Fazenda aceitou os recursos de uma futura privatização dos serviços para completar a "conta gráfica" (os $20 \%$ que são pagos à vista) da renegociação da dívida da prefeitura, no valor de $\mathrm{R} \$ 1,9$ bilhão. Por outro lado, pouco mais tarde, os serviços de saneamento da cidade de Manaus - base dos negócios de Miranda - foram concedidos à Lyonnaise.

6. O principal entrave para a privatização das Cesbs é que essas empresas são concessionárias dos municípios e para privatizar deveriam receber autorização de todas as Câmaras Municipais dos municípios concedentes. Por esse motivo, os governadores dos Estados do Rio de Janeiro e Espírito Santo, entre outros, não conseguiram privatizar suas empresas. Uma alternativa tentada foi dividir a empresa e privatizar apenas nos municípios onde as Câmaras Municipais autorizaram, mas este caminho só deu certo no Amazonas. De fato, existem situações muito diferentes. No Município de São Paulo, por exemplo, o governo do Estado é responsável pelos serviços desde 1893 e a Sabesp (de propriedade do governo) aí obtém mais de $70 \%$ do seu faturamento e não tem contrato formal com a empresa. Rescindir um "contrato informal" de mais de 100 anos demandará, no futuro, um longo processo judicial.

7. Este número, 50 mil habitantes, é bastante arbitrário porque o interesse privado também depende da qualidade dos sistemas de saneamento existentes; mas serve para nossos propósitos pois alguma variação de população, para mais ou para menos, não mudaria a lógica da análise.
8. Os serviços municipais de saneamento são oferecidos por algum órgão da administração direta ou por uma autarquia municipal, que responde pelo nome genérico de Serviços Autônomos de Água e Esgoto (SAAEs) ou Departamentos Autônomos de Água e Esgotos (DAAEs). Quando se menciona algum desses serviços municipais, faz-se com o nome de DAAE/SAAE, embora alguns não sejam autarquias.

9. Vários outros prefeitos também tentaram privatizar os serviços de saneamento de suas cidades, como o de Campinas, por exemplo, mas não chegaram a enviar o PL à Câmara Municipal porque, em consultas prévias, perceberam que havia poucas possibilidades do projeto ser aprovado.

10. Estes dados são do censo realizado pela Fundação IBGE em 1991. Desse ano em diante as coberturas melhoram em muitos municípios. Porém, ante a falta de informações completas e confiáveis, optou-se por utilizar as do IBGE.

11. Por exemplo, dois anos após obter a concessão, a “Águas de Limeira” havia diminuído o número de funcionários de 440 para 220.

12. O BNDES apenas se convenceu de que esse modelo é o adequado para o setor de saneamento somente no ano 2000. (O Estado de S.Paulo, 10/10/2000).

13. O Programa Estadual de Financiamentos para obras de Saneamento (Sanebase) foi criado em 1991. É um programa de crédito para os sistemas municipais, financiado com recursos do orçamento do Estado e intermediado pela Sabesp. O Fundo Estadual de Recursos Hídricos (Fehidro) foi instituído pela Lei Estadual $n^{\circ}$ 7.663/91 para financiar, também com recursos orçamentários, programas estaduais e municipais de conservação de recursos hídricos.

14. O problema das Cesbs em participar de concorrência pública é que elas não se sujeitam às normas das empresas privadas, quanto às obrigações trabalhistas e tributárias, exigidas na Lei de Concessões.

15. No município de Leme, por exemplo, alguns padres faziam campanha contra a privatização nas missas.

16. O parecer $n^{\circ}$ 00925/010/96 do conselheiro Fúlvio Biazzi apontou quatro irregularidades: 1) que o contrato de concessão tinha sido homologado no mesmo dia em que se adjudicou a sentença; 2) que o edital de concorrência não indicou os bens reversíveis; 3 ) que a classificação final das empresas participantes da licitação e suas propostas não foram tornadas públicas; e 4) que o contrato de concessão não tinha referências sobre o valor total da concessão.

17. Em dezembro de 1999, depois de quatro anos de processo, a Justiça cancelou o contrato de concessão apontando inúmeras irregularidades. A empresa "Águas de Limeira" apelou da decisão.

18. Nessas duas cidades argentinas, os processos de privatização dos serviços de água foram cancelados na justiça por denúncias de acordo prévio e manipulação do edital entre essa empresa e as autoridades que comandavam o processo (Assemae, 1996:13).

19. Um ex-deputado estadual que participou do movimento, em depoimento ao autor desse trabalho, disse: "Nós fizemos uma audiência pública e outros debates na Câmara Municipal, em que convidamos pessoas do setor. Nesse sentido foi extremamente importante a ajuda de Rodolfo Costa e Silva, João Batista Peixoto e a assessora jurídica Tânia Nahum [todos da Assemae]. Eles nos passaram muitas informações, imprescindíveis para enfrentar com sucesso a privatização, porque tínhamos dificuldades para enfrentar os aspectos técnicos do processo".

20. Tratava-se de pessoas que ocuparam cargos de direção na Sabesp durante o governo Fleury. No município de Catanduva a consultoria prévia também foi realizada por pessoas da Fundação Escola de Sociologia e Política de São Paulo.

21. Entre a Lei Municipal n ${ }^{\circ} 3.763 / 96$, que autorizou a concessão, e o edital existiam critérios de julgamentos diferentes para decidir qual seria a empresa vencedora.

\section{REFERÊNCIAS BIBLIOGRÁFICAS}

ARAUJO, R. e LOUREIRO, R. Limites e possibilidades de descentralização administrativa: o setor de saneamento básico no Estado de São Paulo. São Paulo, Fundap, 1998.

ARRETCHE, M. O processo de descentralização das políticas sociais no Brasil e seus determinantes. Tese de Doutorado. Campinas, Unicamp, 1998, mimeo. Política nacional de saneamento: a reestruturação das companhias estaduais. Brasília, Ipea, 1999.

ARRETCHE, M. e AMARAL, K. "A regulação na perspectiva das entidades representativas do setor saneamento". Relatório $n^{\circ}$ 7, São Paulo, Fundap, 1995. 
ASSEMAE. Concessões privadas: radiografia de um equívoco. Brasília, Assemae/ Água e Vida, 1996.

ASSEMAE/FNS. Diagnóstico nacional dos serviços municipais de saneamento. São Paulo, Água e Vida/Assemae /FNS, 1995.

BARAGLIO GRANJA, S. Desestatização e privatização da infra-estrutura do setor de saneamento em São Paulo. São Paulo, Fundap, 1996.

BNDES. Informe Infra-Estrutura. Rio de Janeiro, n.20 e 23, 1998.

CABES XVII. Catálogo brasileiro de engenharia sanitária e ambiental: guia do saneamento ambiental no Brasil 1992/1993. Rio de Janeiro, ABES, 1994.

CAMPELO DE SOUZA, M. do C. Estado e partidos políticos no Brasil (1930 a 1964). São Paulo, Ed. Alfa Omega, 1976.

COSTA, G. Avaliação da política de planejamento implantada no setor de saneamento básico no periodo 1971/83 em São Paulo. São Paulo, 1992, mimeo.

COTTA, T. Burocracia, capacidade de Estado e mudança estrutural. Brasília, ENAP, 1997.

DINIZ, E. Empresariado, sindicatos y politica econômica en la nueva república: Brasil, 1985-1986. Estabilización y respuesta social. Santiago, PrealcOIT, 1990.

. "Governabilidade, democracia e reforma do Estado: os desafios da construção de uma nova ordem no Brasil dos anos 90". Revista Dados. Rio de Janeiro, v.3, n.3, 1995.

DINIZ, E. e BOSCHI, R.R. "A consolidação democrática no Brasil: atores políticos, processos sociais e intermediação de interesses”. In: DINIZ, E.; BOSCHI R.R. e LESSA R. (orgs.). Modernização e consolidação democrática no Brasil: dilemas da Nova República. São Paulo, Vértice, 1989.

FONSECA, F. e SANCHEZ, O. O processo de reforma do Estado nas unidades federativas: o caso de São Paulo. São Paulo, Cedec, 1998, mimeo.

HAGGARD, S. e KAUFMAN, R. "Estado y reforma económica: la iniciación y consolidación de las políticas de mercado". Revista Desarrollo Económico. Buenos Aires, n.139, 1995.

IBGE. Censos demográficos 1970/1980/1991. Rio de Janeiro.
JOHNSON, B.; SAES, F.; TEIXEIRA, H. e WRIGHT, J. Serviços públicos no Brasil: mudanças e perspectivas. São Paulo, Ed. Blücher, 1996.

JORGE, W. A política nacional de saneamento pós-64. Tese de Doutorado. São Paulo, FAU/USP, 1987, mimeo.

LIMONGI, F. e FIGUEIREDO, A. "Os partidos políticos na Câmara dos Deputados". Dados. Revista de Ciências Sociais. Rio de Janeiro, v.38, n.3, 1995.

MARQUES, C. Agências estatais, engenheiros e empreiteiras na produção de infra-estrutura urbana no Rio de Janeiro. Tese de Doutorado. São Paulo, Unicamp, 1998.

MOREIRA, T. Saneamento básico: desafios e oportunidades. Rio de Janeiro, BNDES, 1996.

. A hora e a vez do saneamento. Rio de Janeiro, BNDES, 1998.

MULLER, P. "Un schéma dánalyse des politiques sectorielles". Revue francaise de sciense politique. Paris, Presses de la fondation nationale des sciences politiques, n.2, Avril, 1986.

OLIVEIRA, C. e SANCHEZ, O. "Saneamento básico no Brasil e no Estado de São Paulo". Cadernos Cedec. São Paulo, n.62, 1996.

OLSON, M. The rise and decline of nations: economic growth, stagflation, and social rigidities. New Haven and London, Yale University Press, 1982.

OWEN, D.; ISKANDAR, S. e TAYLOR, A. "Por todo el planeta, privatizaciones con acento frances". Jornal El Clarin. Buenos Aires, 29/08/1999.

PEIXOTO, J.B. O barulho das águas. São Paulo, Água e Vida, 1994.

SANCHEZ, O. Águas de São Paulo: as tentativas de privatização do saneamento (1995/8). Dissertação de Mestrado. São Paulo, DCP/USP, 2000.

SEADE. Perfil municipal 1980/91. São Paulo, 1993.

SECRETARIA DE ECONOMIA E PLANEJAMENTO. Saneamento básico, 1970/ São Paulo. São Paulo, 1970.

SERRA, G. Urbanização e centralismo autoritário. Tese de livre-docência. São Paulo, FAU/USP, 1987.

VELASCO Jr., L. “A economia política das políticas públicas: as privatizações e a reforma do Estado". Textos para discussão 54. Rio de Janeiro, BNDES, 1997. 